\title{
The sorption of metal ions on nanoscale zero-valent iron
}

\author{
Tomasz Suponik ${ }^{1, *}$, Marcin Popczyk ${ }^{1}$, and Piotr Pierzyna ${ }^{1}$ \\ ${ }^{1}$ Silesian University of Technology, Faculty of Mining and Geology, 44-100 Gliwice ul. Akademicka 2, Poland
}

\begin{abstract}
The injection of the colloidal suspensions of nano-iron (nZVI) into an aquifer is a novel method of removing metal ions from acidic water. In the batch tests, the equilibrium study of the sorption of metal ions, $\mathrm{Cu}(\mathrm{II})$ and $\mathrm{Zn}(\mathrm{II})$, on Green Tea nanoscale Zero-Valent Ion (GT-nZVI) was carried out. The sorption of metal ions on this reactive material was described using the Langmuir, Freundlich and Sips models. This last model described in a better way the sorption equilibrium in the tested range of concentrations and temperature. The value of determination coefficient $\left(\mathrm{R}^{2}\right)$ for the Sips model, for copper and zinc, was 0.9735 to 0.9995 , respectively. GT-nZVI has very good properties in removing $\mathrm{Cu}(\mathrm{II})$ and $\mathrm{Zn}$ (II) from acidic water. The high values of qmaxs, the maximum adsorption capacity in the Sips model, amounting to 348.0 and $267.3 \mathrm{mg} / \mathrm{g}$ for $\mathrm{Cu}(\mathrm{II})$ and $\mathrm{Zn}(\mathrm{II})$, indicate the high adsorption capacity of GT-nZVI. The analyzed metals have good or very good affinity with GT-nZVI.
\end{abstract}

\section{Introduction}

Waste materials resulting from the mining of non-ferrous metal ores and hard coal, as well as from the manufacturing process of non-ferrous metals, accumulated at industrial waste disposal sites contain metal minerals and, as a result, may affect the quality of ground and surface water in the southern areas of Poland. The leachate from these places may contain various toxic metals which may cause a risk to the environment.

In order to protect ground and surface water from leachates containing metal contaminants the suspension of nano-ZVI may be injected into contaminated aquifer [1]. In the study, the nanoscale zero-valent iron was obtained by reducing $\mathrm{Fe}(\mathrm{II})$ with a solution of green tea (GT). The polyphenols were responsible for the reduction properties of this tea [2]. GT is an effective, cheap and environmentally friendly alternative to other ways of obtaining nZVI. In accordance with Hoag et al. [3] the polyphenolic matrix can act as a capping agent that protects the iron nanoparticles from premature oxidation. In this way, the effect of removing metal ions by zerovalent iron can be intensified by biosorption on the coating of polyphenolic compounds. Biosorption on them is the process of selectively binding compounds (e.g. metal ions) on the surface of biological material by the presence of specific functional groups. The quality and quantity of these groups is not the same for each biosorbent. Therefore, the binding mechanism of the selected compounds is different. It may be based on physical adsorption, chelation [4], complexation, micro precipitation or ion exchange [5].

The processes of the removal of metal ions from water (directly) on $\mathrm{Fe}(0)$ are: reductive precipitation that lead to the metallic form, co-precipitation with iron in the form of oxides and/or hydroxides, precipitation as a result of an increase in $\mathrm{pH}$ and adsorption on the surface of iron corrosion products [6]. The type of processes depends on the type of metal removed, the other accompanying substances and the physicochemical conditions in the ZVI bed, mainly the $\mathrm{pH}$ of the water.

The aim of the study was to assess the equilibrium sorption of metal ions, $\mathrm{Cu}(\mathrm{II})$ and $\mathrm{Zn}(\mathrm{II})$, on GT-nZVI. The equilibrium of these processes were described using the Langmuir, Freundlich and Sips models.

\section{Materials and methods}

\subsection{Synthesis of GT-nZVI}

Nanoscale zero-valent iron particles was prepared in aqueous solutions by way of the reduction of ferrous iron $\mathrm{Fe}(\mathrm{II})$ using a solution of green tea (GT). The method was inspired by article written by Mystrioti et al. [7]. A method of preparing the suspension of green tea nanoscale zero-valent iron GT-nZVI was presented in the papers $[1,7,8]$. The 1:2 volume ratio of the GT solution to the $\mathrm{Fe}(\mathrm{II})$ solution were vigorously mixed in a flask reactor (see Fig. 1) at room temperature for an additional 15 minutes after the titration of GT. The solutions in the flask were mixed with a mechanical stirrer at $120 \mathrm{rpm}$. Through titration at a rate of $1.0 \mathrm{~cm}^{3} / \mathrm{s}$, the solution of GT was introduced to reduce ferrous ions to zero-valent iron $\mathrm{Fe}(0)$.

The Loyd brand of green tea was the source of polyphenolic compounds. An immersion of dry green tea in deionized water at a temperature of $80-90^{\circ} \mathrm{C}$ for 30 minutes, was the way of preparing the solution. It was filtered with the vacuum filtration, using a filter paper of $0.45 \mu \mathrm{m}$ pore size. The ratio of green tea leaves to deionized water, amounted to $1 \mathrm{~g} / 50 \mathrm{ml}$, while the ratio of

* Corresponding author: tomasz.suponik@polsl.pl 
$\mathrm{FeCl}_{2} \cdot 4 \mathrm{H}_{2} \mathrm{O}$ to deionized water was $1.35 \mathrm{~g} / 50 \mathrm{ml}$. $\mathrm{FeCl}_{2} \mathrm{X} 4 \mathrm{H}_{2} \mathrm{O}$ was dissolved in deionised water and stirred under strong ultrasonic agitation a short time before introducing the GT solution [1].

The $\mathrm{pH}$, conductivity and oxidation-reduction potential (ORP) in the GT-nZVI suspensions were 1.73, $10.7 \mathrm{mS} / \mathrm{cm}$ and $499 \mathrm{mV}$, respectively.

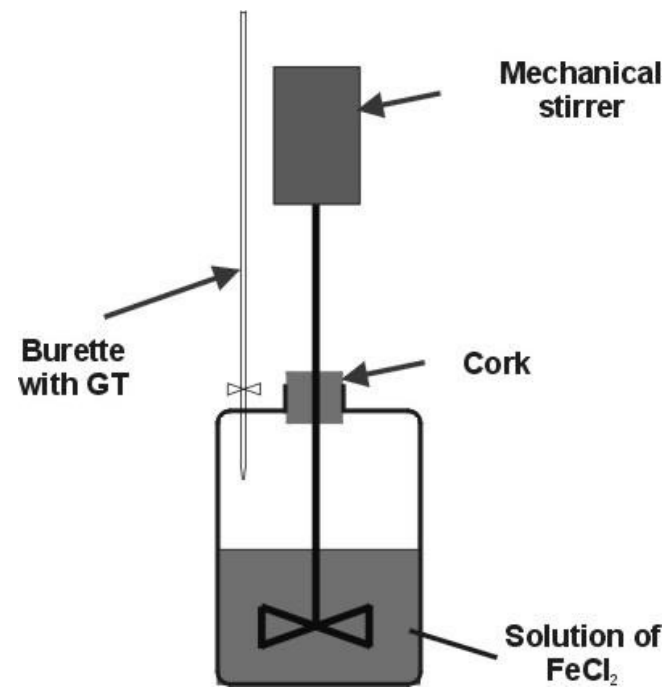

Fig. 1. Laboratory set-up for GT-nZVI synthesis [1].

\subsection{Characteristics of the batch test}

The several of experiments were done to study the capability of GT-nZVI in the removal of $\mathrm{Cu}$ (II) and Zn(II) from water in different initial concentrations of metals. For all these tests, the wastewater was prepared before. Metal ion solutions (copper, zinc) were prepared by dissolving the appropriate metal salts $\left(\mathrm{CuSO}_{4} \times 5 \mathrm{H}_{2} \mathrm{O}\right.$, $\mathrm{ZnSO}_{4} \times 7 \mathrm{H}_{2} \mathrm{O}$ ) in distillated water. Always only one metal salts was dissolved in water. The concentrations of metal in the solutions were always higher than the allowable concentration of individual metals, within the meaning of legal regulations provided in the Journal of Laws, 2014, item 1800. The concentrations were in the ranges of 10 $500 \mathrm{mg} / \mathrm{dm}^{3}$, while the $\mathrm{pHs}$ for the solution of copper, zinc were $4.7,5.3$, respectively.

The tests were conducted in a programmable MULTI BIO RS-24 BIOSAN rotator equipped with plastic tubes filled with metal solution. Then the $0.5 \mathrm{ml}$ of GT-nZVI was added into each of the solution. The $0.5 \mathrm{ml}$ of suspension corresponds to $0.0067 \mathrm{~g}$ of dry matter obtained after the evaporation of water. This mass was used, as a mass of GT-nZVI, for calculations of the parameters of isotherms. However, this material is not consistent with the amount of GT-nZVI. The mass of iron is much lower. Using a lower weight, the sorption capacity of GT-nZVI would be much higher. In accordance with Mystrioti et al. [8], it was found that only ca. $27 \%$ of the total Fe was reduced to its elemental state. Namely, the produced GTnZVI suspensions contained approximately $1.3 \mathrm{~g} / \mathrm{dm}^{3}$ of $\mathrm{Fe}$ in the form of nZVI solid particles and $3.7 \mathrm{~g} / \mathrm{dm}^{3}$ in the form of $\mathrm{Fe}(\mathrm{II})$ aqueous ions.
In order to eliminate the headspace (a gaseous phase above the solution) the total volume of the sample in the tube amounted to $58 \mathrm{~cm}^{3}$. All these experiments were carried out in a laboratory temperature of $22^{\circ} \mathrm{C} \pm 2{ }^{\circ} \mathrm{C}$.

A two-minute orbital rotation was applied for each sample in the rotator (40 rpm), after which a six-second reciprocal motion (with a turning angle equal to $90^{\circ}$ ) with vibration followed. This sequence of shaking was repeatedly reiterated. The sequence continued for 120 minutes.

\subsection{Measurement methods}

After shaking the samples, the solutions were passed through filter paper of $0.45 \mu \mathrm{m}$ pore size and assessed. The temperature, $\mathrm{pH}$, the redox potential and the electrolytic conductivity were determined using electrometric methods (with the following meters: PORTAMESS $913 \mathrm{pH}$ with a SenTix 41 combination electrode; PORTAMESS $913 \mathrm{pH}$ with a POLYPLAST ORP electrode; PORTAMESS 913 Cound). Also, the following determinations were made with regards to water:

- concentrations of $\mathrm{Cu}_{\text {tot }}$ : Spectrophotometer DR5000 HachLange by the bicinchoninate method (method 8506 of Hach Co.), at wavelength $560 \mathrm{~nm}$,

- concentrations of $\mathrm{Zn}_{\text {tot }}$ : Spectrophotometer DR5000 HachLange by the Zincon method (method 8009 of Hach Co.), at wavelength $620 \mathrm{~nm}$,

- concentrations of $\mathrm{SO}_{4}^{2-}$ : Spectrophotometer DR5000 HachLange by the SulfaVer 4 method (method 8051 of Hach Co.) at wavelength $450 \mathrm{~nm}$.

The measurements were carried out four times. The results were calculated as an arithmetic mean.

\subsection{Mathematical description}

The changes in the concentration of metal ions as a result of the use of GT-nZVI were calculated in accordance with the equation:

$$
q_{t}=\frac{\left(C_{0}-C_{t}\right) \cdot V}{m}
$$

where :

$\mathrm{q}_{\mathrm{t}}$ - the amount of metal ions adsorbed by the mass of $\mathrm{nZVI}, \mathrm{mg} / \mathrm{g}$,

$\mathrm{C}_{0} \quad$ - the concentration of metal ions in water before the batch test, $\mathrm{mg} / \mathrm{dm}^{3}$,

$\mathrm{C}_{t}$ the concentration of metal ions in the water after 120 minutes, $\mathrm{mg} / \mathrm{dm}^{3}$,

$\mathrm{V}$ - the volume of solution, $\mathrm{dm}^{3}$,

$\mathrm{m} \quad-$ the mass of nZVI used in the test, g.

In order to determine the correlation between the amount of metals adsorbed on the surface of GT-nZVI and the amount of metals remaining in the solution, the three nonlinear mathematical models were used being the Freundlich (eq. 2) [9] and Langmuir (eq.3) [10] and Sips models.

$$
q_{e q}=K_{f} \cdot C_{e q}^{\frac{1}{n_{f}}}
$$


where :

$\mathrm{q}_{\text {eq }} \quad$ - amount of metal ions adsorbed by the mass of $\mathrm{nZVI}$ at equilibrium, $\mathrm{mg} / \mathrm{g}$,

$\mathrm{C}_{\mathrm{eq}} \quad$ - the equilibrium concentration of metal ions in water after batch test, $\mathrm{mg} / \mathrm{dm}^{3}$,

$\mathrm{K}_{\mathrm{f}}-$ Freundlich sorption equilibrium constant, $(\mathrm{mg} / \mathrm{g})\left(\mathrm{dm}^{3} / \mathrm{mg}\right)^{1 / \mathrm{n}}$,

$\mathrm{n}_{\mathrm{f}} \quad-$ Freundlich exponent.

$$
q_{e q}=\frac{q_{\operatorname{maxL}} \cdot K_{L} \cdot C_{e q}}{1+K_{L} \cdot C_{e q}}
$$

where :

$\mathrm{K}_{\mathrm{L}} \quad$ - Langmuir equilibrium constant, $\mathrm{dm}^{3} / \mathrm{mg}$,

$\mathrm{q}_{\operatorname{maxL}}-$ maximum sorption capacity in the Langmuir model, $\mathrm{mg} / \mathrm{g}$.

The Sips isotherm is a combination of the Langmuir and Freundlich isotherms and is given in the form [11].

$$
q_{e q}=\frac{q_{\operatorname{maxS}} \cdot K_{S} \cdot c_{e q}^{\frac{1}{n_{S}}}}{1+K_{S} \cdot c_{e q}^{\frac{1}{n_{S}}}}
$$

where :

$\mathrm{K}_{\mathrm{S}} \quad$ - the Sips equilibrium constant, $\left(\mathrm{dm}^{3} / \mathrm{mg}\right)^{1 / \mathrm{n}}$,

$\mathrm{q}_{\operatorname{maxS}}$ - the Sips maximum adsorption capacity, $\mathrm{mg} / \mathrm{g}$,

$\mathrm{n}_{\mathrm{S}} \quad-$ the Sips model exponent.

\section{Results and discussion}

For the GT-nZVI, the sorption isotherms of metal ions were determined as a function of their concentration. Figures 2, 3 show isotherms for $\mathrm{Cu}(\mathrm{II}), \mathrm{Zn}(\mathrm{II})$, respectively. As was presented in these Figures, the sorption capacity of GT-nZVI increased for the initial concentration of metal ions in the solution in the range of 10 to $100 \mathrm{mg} / \mathrm{dm}^{3}$. Then the capacity grew much slower.

The obtained results correlate well with the selected equations of adsorption equilibrium (see Table 1). This is evidenced by the high or very high values of $\mathrm{R}^{2}$. The higher values of R2 in the Sips model, for the both of metals, indicate the best suitability fitting to the results of the experiments. These were 0.9735 and 0.9995 , for copper and zinc, respectively.

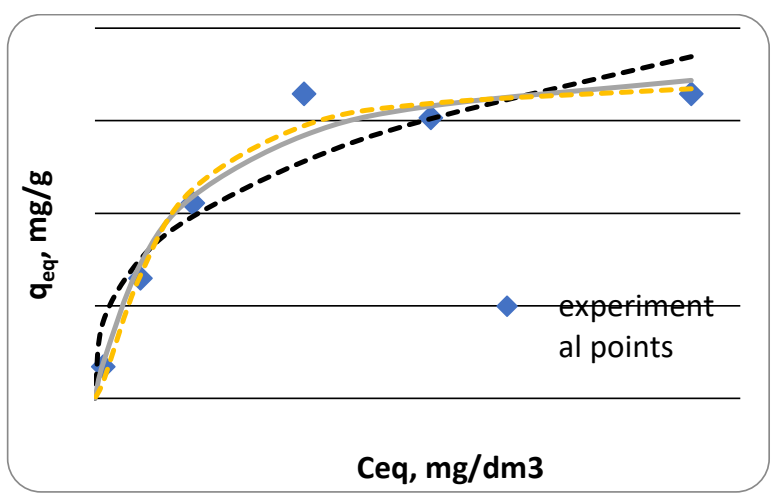

Fig. 2. Equilibrium of the sorption of $\mathrm{Cu}$ (II) on GT-nZVI.

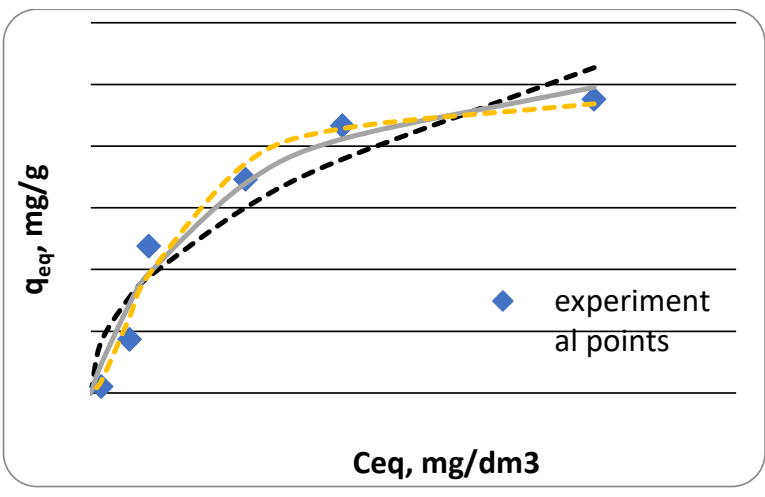

Fig. 3. Equilibrium of the sorption of Zn(II) on GT-nZVI.

Based on the data presented in the table 1, it can also be said that GT-nZVI has very good properties in removing copper and zinc from water.

The high values of $\mathrm{qmax}_{\mathrm{L}}$, in Langmuir's theory, qmax $_{S}$, in Sip's theory, and Kf, in Freundlich's theory, indicate the high adsorption capacity of this material for all analyzed metal ions.

These values were $387.4 \mathrm{mg} / \mathrm{g}, \quad 348.0 \mathrm{mg} / \mathrm{g}$, $43.33(\mathrm{mg} / \mathrm{g})\left(\mathrm{dm}^{3} / \mathrm{mg}\right)^{1 / \mathrm{n}}$, for $\mathrm{Cu}$ (II), and $305.2 \mathrm{mg} / \mathrm{g}$, $267.3 \mathrm{mg} / \mathrm{g}$ and $45.64(\mathrm{mg} / \mathrm{g})\left(\mathrm{dm}^{3} / \mathrm{mg}\right)^{1 / \mathrm{n}}$, for $\mathrm{Zn}(\mathrm{II})$. It should be noted here that ionic strength of solutions was small compared to natural waters.

$1 / \mathrm{n}$ is a function of the force with which the metal ions are sorbed by the adsorbent. The lower the $1 / \mathrm{n}$ (towards zero), the greater the affinity of the substance.

For both tested metals, the value of $1 / \mathrm{n}$ below 1 indicates a normal Sips isotherm and Freundlich isotherm, and the adsorption becomes more heterogeneous as the value of $1 / \mathrm{n}$ gets closer to zero.

Yang et al. [12] studied also the sorption of copper on adsorbent. This was the walnut shell supported nanoscale zero-valent iron. It was prepared from sodium borohydride, iron(II) chloride tetrahydrate, and walnut shell by liquid phase chemical reduction.

The values of $\mathrm{q}_{\operatorname{maxL}}$ and $\mathrm{K}_{\mathrm{L}}$, in the Langmuir model, and $\mathrm{K}_{\mathrm{f}}$ and $1 / \mathrm{n}_{\mathrm{f}}$, in the Freundlich model, were, in the study of Yang et al. [12], $398.4 \mathrm{mg} / \mathrm{g}, 0.029 \mathrm{dm}^{3} / \mathrm{mg}$ and $199.8(\mathrm{mg} / \mathrm{g})\left(\mathrm{dm}^{3} / \mathrm{mg}\right)^{1 / \mathrm{n}}, 0.084$, at ca. $20^{\circ} \mathrm{C}$. These values are of similar magnitude as was obtained with the use of GT-nZVI.

Another study on the sorption of copper on iron was presented by Ayob et al. [13]. They investigated the feasibility of using carboxylmethyl cellulose (CMC)stabilized nano zero valent iron (nZVI) particles for immobilization of $\mathrm{Cu} 2+$ in water. The parameters of Freundlich's isotherm for this material were $\mathrm{K}_{\mathrm{f}}=9.1559(\mathrm{mg} / \mathrm{g})\left(\mathrm{dm}^{3} / \mathrm{mg}\right)^{1 / \mathrm{n}}$ and $\mathrm{n}=3.042$.

In conclusion, it can be said that nano-iron has very good properties in the removal of metal ions from water. The process of water purification by $\mathrm{Fe}(0)$ was probably intensified by biosorption on the coating of polyphenolic compounds. This may be evidenced by the fact that the concentration of sulphates (see Table 2) also decreased, unlike the observations presented in the paper [14]. The parameters such as $\mathrm{pH}$ and ORP (see Table 2 ) were varied in the same way as in the case of $\mathrm{Fe}(0)$ in the form of fine grain steel [14] or in the form of rector with steel sheets 
positioned in parallel inside. This is proof that $\mathrm{Fe}(0)$ itself is reactive.

However, the changes in the values of $\mathrm{pH}$, ORP and sulphate concentrations were very small, because a small amount of GT-nZVI was added to the solutions.

Table 1. The equilibrium parameters of sorption obtained from the Freundlich, Langmuir and Sips isotherms.

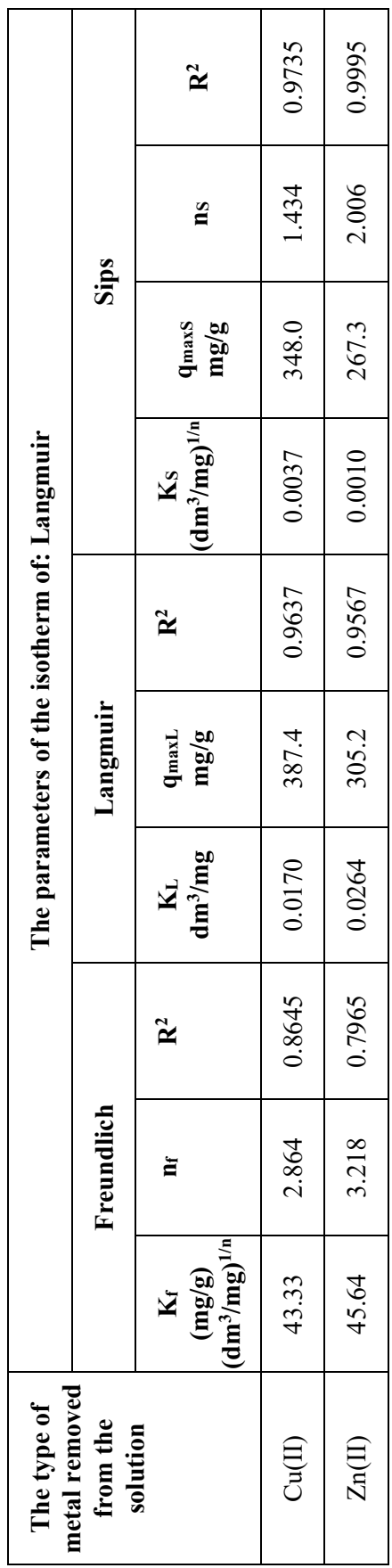

Table 2. The change in the value of $\mathrm{pH}, \mathrm{ORP}$ and sulphate concentrations according to initial metal ions concentration. The positive value means an increase after batch tests, while negative a decrease. The table presents the average values for the analyzed parameters/substances.

\begin{tabular}{|c|c|c|c|c|}
\hline \multirow{6}{*}{ 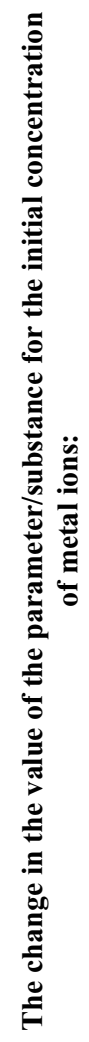 } & 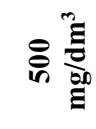 & ¿. & T & $\stackrel{\bigcirc}{7}$ \\
\hline & 戹 & $\begin{array}{l}\overline{0} \\
\dot{+}\end{array}$ & $\exists$ & $\widetilde{a}$ \\
\hline & 突 & $\begin{array}{l}\hat{O} \\
\dot{+}\end{array}$ & 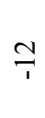 & $\begin{array}{l}\infty \\
\infty \\
1\end{array}$ \\
\hline & $\stackrel{\Xi}{\mathrm{E}}$ & $\begin{array}{l}\stackrel{8}{\circ} \\
\stackrel{+}{+}\end{array}$ & $\stackrel{\infty}{1}$ & $\vec{p}$ \\
\hline & 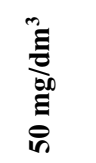 & $\begin{array}{l}\stackrel{0}{0} \\
+\end{array}$ & $\vec{\imath}$ & $\stackrel{\infty}{+}$ \\
\hline & 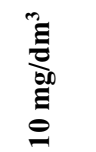 & $\begin{array}{l}\vec{\square} \\
\dot{+}\end{array}$ & $\stackrel{\sim}{\sim}$ & $\underset{r}{\stackrel{1}{r}}$ \\
\hline \multicolumn{2}{|c|}{ 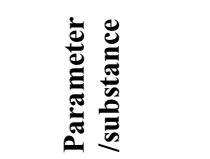 } & 兑 & 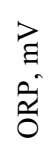 & 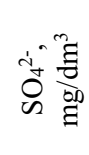 \\
\hline
\end{tabular}

\section{Conclusion}

This study has shown that GT-nZVI is a good material for removing metal ions from acid mine water. This is determined by:

- the very good sorption capacity of GT-nZVI - In Sips model, the $\mathrm{q}_{\operatorname{maxs}}$, were 348.0 and $267.3 \mathrm{mg} / \mathrm{g}$, for copper and zinc, respectively,

- the good affinity of copper and zinc with GT-nZVI - The low value of $1 / \mathrm{n}$, in the Sips theory, amounting to 0.697 and 0.499 for copper and zinc, respectively,

- the dual action of $F(0)$ and biosorbent - The process of water purification by $\mathrm{Fe}(0)$ was probably intensified by biosorption on the coating of polyphenolic compounds, - the size of GT-nZVI and other properties - This material has a large surface area, is inexpensive to use, compared with other reactive materials, and environmentally friendly and, if kept stable, can spread without clogging the pores of the aquifer.

The obtained results of experiments correlate the best with the Sips theory. The determination coefficient $\left(\mathrm{R}^{2}\right)$ was 0.9735 and 0.9995 for copper and zinc, respectively. 


\section{References}

1. T. Suponik, M. Lemanowicz, P. Wrona, E3S Web Conferences, 8, 01048 (2016)

2. Y. Joshi, S., Nanoscale and Microscale Phenomena, (Springer, 2015)

3. G. E. Hoag, J. B. Collins, J. L. Holcomb, J. R. Hoag, M. N. Nadagouda, R. S. Varma, J. Mater. Chem., 19(45), 8671-8677, (2009)

4. R. C. Hider, Z. D. Liu, H.H. Khodr, Meth. Enzymol., 335, 190-203 (2001)

5. D. Podstawczyk, A. Witek-Krowiak, 1, 232-237, (Creativetime, 2015)

6. T. Suponik, M. Blanko, Physicochem. Probl. Mi., 50(1), 359-372 (2014)
7. C. Mystrioti, N. Papassiopi, A. Xenidis, D. Dermatas. M. Chrysochoou, J. Hazard. Mater., 281, 6 (2015)

8. C. Mystrioti, A. Xenidis, N. Papassiopi, J. Geosci. Env. Protec., 2, 28-36 (2014)

9. H.M.F. Freundlich, Phys. Chem., 57, 385 (1906)

10. I. Langmuir, Journal of the American Chemical Society, 38(11), 2221-2295 (1916)

11. O. Hamdaoui, E. Naffrechous, J. Hazard. Mater., 147(1), 381-394 (2007)

12. F. Yang, Y. He, S. Sun, Y. Chang, F. Zha, Z. Lei, J. Appl. Polym. Sci., 133(16), (2016)

13. A.F.I.Z.A.H. Ayob, N. Ismail, T. T. Teng, A.Z. Abdullah, Environ. Prot. Eng., 38(3), 119-131 (2012)

14. T. Suponik, Physicochem. Probl. Mi., 49(1), 16431649 (2013) 